\section{Berry Texture of Table, Wine, and Dual-purpose Grape Cultivars Quantified}

\author{
Akihiko Sato and Masahiko Yamada \\ Department of Grape and Persimmon Research, National Institute of Fruit \\ Tree Science, Akitsu, Hiroshima 729-2494, Japan
}

Additional index words. grape, Vitis vinifera, Vitis labruscana, flesh texture, wine grape, genetic variation, germplasm

\begin{abstract}
The textural properties of grape berry flesh were evaluated with a puncture test using a total of 87 cultivars, consisting of 62 vinifera cultivars (Vitis vinifera L.) and 25 labruscana cultivars (Vitis labruscana Bailey) in order to search cultivars with crisp flesh texture for table grape breeding. Crisp texture is the most desirable texture for tableuse, and was determined as easy breakdown on mastication and firm flesh, which was measured as small deformation at the first major peak (DFP) and large maximum force (MF), respectively, in force-deformation curve of the test. For the vinifera cultivars, the mean values of DFP and MF were significantly smaller and larger in table-use cultivars than wine-use and dual-purpose cultivars, respectively. The result indicated that the vinifera wine-use and the dual-purpose cultivars had soft and non-crisp flesh. Based on the puncture tests, the cultivars with a crisp texture $(2.5 \mathrm{~mm} \geq$ for DFP and $0.9 \mathrm{~N} \leq$ for MF) were limited to 11 vinifera table-use cultivars such as 'Baladi', 'Cardinal', and 'Muscat of Alexandria'; and one vinifera dual-purpose cultivar ('Terbash'). The DFP was generally high in labruscana cultivars, which include table-use and dual-purpose cultivars, resulting in lacking cultivars with crisp texture among labruscana cultivars. These results indicate that the cultivars with a crisp texture were restricted to a small source within vinifera cultivars.
\end{abstract}

Grape (Vitis sp.) is the most important fruit crop in the world, grown over nine million hectares (Alleweldt et al., 1990; Reisch and Pratt, 1996). Today's leading cultivars are European grapes (Vitis vinifera L., vinifera cultivars) (Alleweldt et al., 1990; Alleweldt and Possingham, 1988) and account for more than $90 \%$ of the world's grape production (Winkler, 1962). However, this species requires a warm and dry climate (Hedrick, 1925) and is highly susceptible to fungal diseases such as downy mildew and anthracnose in wet climates (Winkler, 1962). Early colonists failed to establish vinifera cultivars in eastern North America because they lacked sufficient disease resistance and cold hardiness (Einset and Pratt, 1975). To rectify this situation, disease resistant and cold hardy cultivars were developed by crossing among vinifera and species native to the United States. The most commonly incorporated native species was the fox grape $(V$. labrusca L.). Hybrid cultivars having labrusca parentage were classified as Vitis labruscana Bailey (labruscana cultivars) (Bailey and Bailey, 1930), which is now commonly used to designate these cultivars (Cahoon, 1986).

There is a large difference in the texture of the berry flesh of vinifera and labrusca (Galet, 1979). While the flesh of vinifera breaks down fairly easily in the mouth, the flesh of labrusca is difficult to masticate (Bourne, 1979) and forms a gelatinous mass (Galet, 1979). The firm, tough texture of labrusca may account for the limited consumption of the labrusca as

Received for publication 5 Oct. 2001. Accepted for publication 27 Sept. 2002. fresh fruit (Bourne, 1979). However, the firm but easy chewed flesh of the vinifera cultivars is expressed as "crisp," a texture that is more desirable in fresh table grapes.

To measure the textural properties of food turometer (Friedman et al., 1963), and the Instron Universal Testing Machine (Bourne and Mondy, 1967) have been developed and used. The mechanically measured variables most often used to define textural characteristics are force and deformation (distance) (Bourne, 1966), and several variables concerning force and deformation were measured on apple from a force-deformation diagram in Instron Universal Testing Machine (Abbott et al., 1984). The texture and firmness of various fruit crops was puncture and compression tested by this machine (Abbott et al., 1984; Bourne, 1968; Brown, 1988; Lee and Bourne 1980).

Sato et al. (1997) showed the differences in grape berry texture as measured by a flesh puncture test using a Rheometer (an Instron-type machine). The degree of difficulty of breakdown on mastication and the flesh firmness could be measured as a deformation at the first major peak (deformation at first breakdown, DFP), and the maximum force (maximum peak of force, MF) in the force-deformation curve between the perception of a sensory panel and the data obtained instrumentally. The texture of vinifera cultivars was described in the literature as soft, firm, or crisp (Hedrick, 1925; Weinberger and Harmon, 1974). The puncture test revealed that cultivars with "crisp" flesh such as that of the 'Flame Seedless' and 'Muscat products, various instruments such as Texof the test. There was a significant correlation of Alexandria, had a small DFP and a large MF. However, the texture of the labruscana described as tough or tender (Hedrick, 1925; Slate et al., 1962) showed a wide variation in both the DFP and MF in the test. The "tough" flesh was that of a large DFP and MF (difficult to breakdown in mastication and firm flesh), while "tender" flesh had a small DFP and MF (Sato et al., 1997).

The texture of wine grapes is softer than that of table grapes (Mullin et al., 1992), and there is little published research on the instrumental measurements of the texture of wine-use and dual-purpose cultivars. Lee and Bourne (1980) tried to measure the puncture force of the berry flesh of a number of table and wine grapes during maturation using a plunger with a 0.9 $\mathrm{mm}$ diameter, but the firmness of the wine cultivars Riesling and Chardonnay was too soft to measure at harvest.

In Japan, with much rainfall in the growing season, labruscana cultivars have been primarily grown as table grapes. However, consumers demand a high degree of quality from the vinifera cultivars, in particular, a crisp texture and a muscat flavor. The National Institute of Fruit Tree Science (NIFTS) has been conducting table grape breeding for more than 30 years to improve quality, berry size, and disease resistance. Crosses have been made among vinifera table-use and labruscana cultivars and selections. For the breeding, it is important to clarify the germplasm with crisp texture, because crosses among cultivars with non-crisp flesh texture will rarely yield offspring with a crisp texture.

Instrumental evaluation of flesh texture is more objective and stable than sensory tests, which are likely to fluctuate depending on testpersons. Sato et al. (1997) measured the flesh texture of a total of 40 grape cultivars without wine-use cultivars by instrument. Clarifying the degree of genetic diversity in grape fruit quality of a large number of cultivars, including wine-use and dual-purpose cultivars, will be useful in breeding. Objectives of this study were to : 1) measure by instrument the variation of berry texture of a total of 87 vinifera and labruscana cultivars for table-use, wine-use, and dual-purpose; and 2) identify the source of a crisp flesh texture in vinifera and labruscana cultivars.

\section{Materials and Methods}

All plant material was obtained from the vineyard of the Dept. of Grape and Persimmon Research of the NIFTS, Akitsu, Hiroshima, Japan. A total of 87 grape cultivars were used in this study encompassing 27 table-use (vinifera table-use cultivars), 23 wine-use (vinifera wine-use cultivars), and 12 dual-purpose (vinifera dual-purpose cultivar) of Vitis vinifera L., 17 table-use (labruscana table-use cultivars), and 8 dualpurpose (labruscana dual-purpose cultivars) of Vitis labruscana Bailey. The use for each cultivar was classified according to Winkler (1962), Galet (1979), Hedrick (1925), Slate et al. (1962), and the World Wide Web page of Vitis International Variety Catalogue (Federal 
Center for Breeding Research on Cultivated Plants, Germany).

Vines were planted in 1989 , or 1990 , in under-drained vineyard with clay loam to light clay soil, north-south oriented rows, at $0.6 \times$ $6 \mathrm{~m}$ spacing. Vines were 4 or 5 years old in 1993. Planting was random concerning species and usage. The climate is of humid temperate at Akitsu with cool winters (average monthly maximum $8.4{ }^{\circ} \mathrm{C}$ and minimum $0.8{ }^{\circ} \mathrm{C}$ in February) and hot and humid summers (average monthly maximum $30.3{ }^{\circ} \mathrm{C}$ and minimum $22.9^{\circ} \mathrm{C}$ in August). Annual rainfall is 1367 $\mathrm{mm}$.

All vines were pruned to one cane with 6 to 10 buds and to several spurs on a horizontal trellis. Clusters were thinned to one to two clusters per shoot after anthesis. The vines were irrigated a few times in summer, and pest- and disease-controlled. Texture measurements were conducted in 1993 for 21 cultivars, 1994 for 20 cultivars, and 2000 for 46 cultivars, respectively.

One bunch of each cultivar was harvested at its respective ripening time from August to September. The mean daily temperature at harvest ranged from 18.9 to $24.3^{\circ} \mathrm{C}$ in 1993 , from 20.8 to $29.0^{\circ} \mathrm{C}$ in 1994 , and from 22.0 to $27.0^{\circ} \mathrm{C}$ in 2000 .

Flesh puncture test measuring DFP and MF were conducted on the harvest day for each cultivar according to Sato et al. (1997). Before measuring, 10 berries were randomly chosen from each bunch. To measure the DFP and MF, a section of flesh that was 8-mm thick was cut longitudinally from each berry and subjected to a puncture test. The berry sample was mounted on the stage of the Rheometer (model NRM-2010J-CW; Fudoh, Tokyo) with a 4-mm diameter hole.

Lee and Bourne (1980) had previously measured the puncture force in unripe berries with a 0.9-mm plunger to avoid the seeds. However, the firmness of the wine grapes could not be measured with the $0.9-\mathrm{mm}$ plunger at their ripening time because the force was too small. We therefore, used a plunger with a 3-mm diameter at a penetration rate of $50.0 \mathrm{~mm} / \mathrm{min}$. The force for compression and the distance from the surface of the sample were recorded as the forcedeformation curve in chart. The deformation axis $(\mathrm{X})$ of the chart in the recorder was driven at $200 \mathrm{~mm} / \mathrm{min}$, exactly four times the speed of the penetration rate. The force axis (Y) was determined at $1.96 \mathrm{~N}$ as $200 \mathrm{~mm}$. The value of deformation at the first major peak (DFP), and maximum force (MF) were obtained from the force-deformation curve on this chart. DFP was calculated as $1 / 4$ of the direct value on the chart, and MF was given as the direct value.

Environmental variance estimates and heritability in a broad sense provide information on the accuracy of the measurements (Yamada et al., 1993). Sato et al. (2000) provided the environmental variance components of DFPand MF for grape cultivars at Akitsu measured in the same way as the present study. They used the log-transformed value to improve the normality of the distribution of the residual estimates in the model of analysis of variance (ANOVA). According to Sato et al. (2000), an environmen- tal variance $\left(\sigma_{\mathrm{E}}^{2}\right)$ of an observed DFP and MF value in each cultivar can be expressed after log-transformed as

$$
\begin{aligned}
\sigma_{\mathrm{E}}^{2}= & \sigma_{\mathrm{b}}^{2} /(\mathrm{bcvy})+\sigma_{\mathrm{c}}^{2} /(\mathrm{cvy})+\sigma_{\mathrm{v}}^{2} / \\
& \mathrm{v}+\sigma_{\mathrm{vy}}^{2} /(\mathrm{vy})+\sigma_{\mathrm{gy}}^{2} / \mathrm{y}+\sigma_{\mathrm{y}}^{2} / \mathrm{y}
\end{aligned}
$$

where $\sigma_{b}^{2}$ is the variance among berries within a cluster, $\sigma^{2}$ is the variance among clusters within a vine, $\sigma^{2}$ is the variance among vine within a genotype, $\sigma_{v y}^{2}$ is the variance due to the interaction between vine and year, $\sigma_{g y}^{2}$ is the variance due to the interaction between genotype and year, $\sigma_{v}^{2}$ is the variance due to year, $y$ is the number of years repeated, $v$ is the number of vines, $c$ is the number of clusters, and $b$ is the number of berries. The environmental variance components were obtained from a previous report (Sato et al., 2000). Here, the repetition of the measurement of the DFP and MF was : $b=10, c=1, v=1$, and $y=1$ because 10 berries were taken from one cluster of one vine for each cultivar without yearly repetition.
Then, $\sigma_{\mathrm{E}}^{2}$ was estimated as

$$
\sigma_{\mathrm{E}}^{2}=\sigma_{\mathrm{b}}^{2} / 10+\sigma^{2}{ }_{\mathrm{c}}+\sigma^{2}{ }_{\mathrm{v}}+\sigma^{2}{ }_{\mathrm{vy}}+\sigma^{2}{ }_{\mathrm{gy}}+\sigma_{\mathrm{y}}^{2}
$$

Heritability in a broad sense was defined as $\left(\sigma_{\mathrm{P}}^{2}-\sigma_{\mathrm{E}}^{2}\right) / \sigma_{\mathrm{P}}^{2}$, where $\sigma_{\mathrm{P}}^{2}$ is the variance among the mean values for each cultivar after log-transformation. The heritability shows the magnitude of genetic effect as compared with environmental fluctuations for DFP and MF in the present study.

\section{Results and Discussion}

High broad-sense heritabilities $(0.87$ for DFP and 0.84 for MF) were obtained using 10 berries of one bunch, one vine, and one year, indicating that the variations are primarily of genetic origin for both DFP and MF.

Vinifera cultivars showed a small DFP $(2.45 \mathrm{~mm})$ near the half of that of labruscana cultivars (Table 1). Because the mean values were correlated with standard deviations, data

\begin{tabular}{|c|c|c|c|c|}
\hline \multirow[b]{2}{*}{ Species } & \multirow[b]{2}{*}{ Usage } & \multirow[b]{2}{*}{ Cultivar } & \multicolumn{2}{|c|}{ Berry texture $^{y}$} \\
\hline & & & $\overline{\mathrm{DFP}}(\mathrm{mm})$ & MF (Newton) \\
\hline \multirow{46}{*}{ Vitis vinifera L. } & \multirow[t]{27}{*}{ Table } & Alphonse Lavalee & 1.80 & 0.63 \\
\hline & & Baladi & 2.19 & 1.64 \\
\hline & & Black Hamburg & 2.67 & 0.51 \\
\hline & & Black Prince & 2.68 & 0.76 \\
\hline & & Cardinal & 1.42 & 0.94 \\
\hline & & Centennial & 1.65 & 0.36 \\
\hline & & Emperor & 2.84 & 0.96 \\
\hline & & Exotic & 1.78 & 1.33 \\
\hline & & Flame Seedless & 2.08 & 1.18 \\
\hline & & Guzal Kara & 1.92 & 0.76 \\
\hline & & Hiro Hamburg & 3.80 & 0.39 \\
\hline & & Italia & 2.48 & 0.67 \\
\hline & & July Muscat & 2.22 & 0.64 \\
\hline & & Katta Kurgan & 2.30 & 1.06 \\
\hline & & Madeleine Celine & 2.14 & 0.71 \\
\hline & & Malaga & 2.37 & 0.95 \\
\hline & & Muscat Hamburg & 0.91 & 0.12 \\
\hline & & Muscat of Alexandria & 2.04 & 1.05 \\
\hline & & Neo Muscat & 2.19 & 0.59 \\
\hline & & Nimrang & 2.18 & 1.39 \\
\hline & & Niunai & 1.63 & 0.96 \\
\hline & & Perlette & 1.68 & 1.08 \\
\hline & & Pizzutello Bianco & 1.10 & 0.58 \\
\hline & & Rish Baba & 1.22 & 0.56 \\
\hline & & Rizamat & 1.65 & 0.98 \\
\hline & & Rosaki & 2.26 & 0.83 \\
\hline & & Sekirei & 2.31 & 0.62 \\
\hline & \multirow[t]{19}{*}{ Wine } & Alimshak & 2.26 & 0.38 \\
\hline & & Blaufaenkisch & 3.13 & 0.22 \\
\hline & & Budeshuri Tetri & 2.31 & 0.53 \\
\hline & & Cabernet Franc & 2.50 & 0.31 \\
\hline & & Cabernet Sauvignon & 2.31 & 0.37 \\
\hline & & Chardonnay & 4.82 & 0.20 \\
\hline & & Chenin Blanc & 2.04 & 0.28 \\
\hline & & Kelner & 5.04 & 0.30 \\
\hline & & Khikhvi & 1.99 & 0.28 \\
\hline & & Kokur Beli & 2.31 & 0.27 \\
\hline & & Matrasa & 4.31 & 0.44 \\
\hline & & Melon & 3.53 & 0.35 \\
\hline & & Mission & 2.44 & 0.61 \\
\hline & & Neuburger & 1.16 & 0.21 \\
\hline & & Ortega & 1.83 & 0.67 \\
\hline & & Perle von Alzey & 2.60 & 0.48 \\
\hline & & Pinot Noir & 1.75 & 0.14 \\
\hline & & \multirow[t]{2}{*}{ Plavaj } & 4.04 & 0.24 \\
\hline & & & \multicolumn{2}{|c|}{ continued on next page } \\
\hline
\end{tabular}

Table 1. Variation of deformation at the first major peak (DFP) and maximum force (MF) of grape cultivars of different origin and usage. ${ }^{\mathrm{z}}$ 


\section{Breeding, Cultivars, Rootstocks, \& Germplasm Resources}

were log-transformed. The variances after logtransformation were $0.025,0.017,0.015,0.034$, and 0.021 for the vinifera (wine-use, table-use, and dual-purpose), and labruscana cultivars

Table 1. Continued.

\begin{tabular}{|c|c|c|c|c|c|}
\hline \multirow[b]{2}{*}{ Species } & \multirow[b]{2}{*}{ Usage } & \multirow{2}{*}{\multicolumn{2}{|c|}{ Cultivar }} & \multicolumn{2}{|c|}{ Berry texture $^{y}$} \\
\hline & & & & $\mathrm{DFP}(\mathrm{mm})$ & MF (Newton) \\
\hline \multirow[t]{17}{*}{ Vitis viinifera $\mathrm{L}$. } & \multirow[t]{5}{*}{ Wine } & \multicolumn{2}{|l|}{ Rkatsiteli } & 2.32 & 0.29 \\
\hline & & \multicolumn{2}{|l|}{ Rotburger } & 3.67 & 0.30 \\
\hline & & \multicolumn{2}{|c|}{ Ruby Cabernet } & 1.78 & 0.39 \\
\hline & & \multicolumn{2}{|c|}{ Siegerrebe } & 2.04 & 0.40 \\
\hline & & \multicolumn{2}{|c|}{ Sulmer } & 3.59 & 0.29 \\
\hline & Dual-purpose & Chasselas D & & 2.19 & 0.30 \\
\hline & & Chasselas R & & 2.00 & 0.38 \\
\hline & & Kosarotovs & & 2.94 & 0.29 \\
\hline & & Koshu & & 4.39 & 0.58 \\
\hline & & Koshu Sanja & & 2.92 & 0.36 \\
\hline & & Madeleine Ang & evine & 2.13 & 0.48 \\
\hline & & Pukhyakovs & & 2.09 & 0.36 \\
\hline & & Saperavi & & 4.26 & 0.35 \\
\hline & & Sereksija Chjo & nyja & 2.30 & 0.27 \\
\hline & & Tavkveri & & 2.95 & 0.32 \\
\hline & & Terbash & & 2.02 & 0.98 \\
\hline & & Vesarga Bel & & 2.00 & 0.46 \\
\hline Vitis labruscaba Bailey & Table & Athens & & 3.56 & 0.53 \\
\hline & & Buffalo & & 4.52 & 0.98 \\
\hline & & Campbell Ea & & 6.38 & 1.40 \\
\hline & & Fredonia & & 5.12 & 0.79 \\
\hline & & Fujiminor & & 2.49 & 0.79 \\
\hline & & Hanover & & 6.92 & 1.21 \\
\hline & & Kendaia & & 6.67 & 0.91 \\
\hline & & Keuka & & 4.13 & 0.50 \\
\hline & & Himrod & & 3.81 & 0.43 \\
\hline & & Kyoho & & 2.30 & 0.77 \\
\hline & & Naples & & 4.90 & 0.98 \\
\hline & & Niabell & & 6.14 & 0.72 \\
\hline & & Ryuho & & 3.38 & 0.50 \\
\hline & & Schuyler & & 1.98 & 0.45 \\
\hline & & Seneca & & 2.22 & 0.52 \\
\hline & & Soraya & & 2.13 & 0.48 \\
\hline & & Steuben & & 4.75 & 0.71 \\
\hline & Dual-purpose & Alden & & 2.52 & 0.55 \\
\hline & & Bath & & 4.35 & 0.66 \\
\hline & & Concord & & 6.47 & 0.78 \\
\hline & & Delaware & & 4.78 & 0.68 \\
\hline & & Lake Emera & & 6.07 & 0.79 \\
\hline & & Muscat Baile & & 6.70 & 1.38 \\
\hline & & New York Mu & scat & 6.75 & 1.04 \\
\hline & & Niagara & & 5.61 & 0.36 \\
\hline & & & riation of $\mathrm{D}$ & $\mathrm{DFP}$ and $\mathrm{M}$ & in each groups \\
\hline & & & FP & & MF \\
\hline & & Mean $^{x}$ & Variance $^{\mathrm{w}}$ & & $\mathrm{n}^{\mathrm{x}} \quad$ Variance \\
\hline Vitis vinifera & Table & $2.06 \mathrm{c}$ & 0.017 & & 0.051 \\
\hline & Wine & $2.77 \mathrm{~b}$ & 0.025 & & 0.025 \\
\hline & Dual-purpose & $2.68 \mathrm{~b}$ & 0.015 & & 0.025 \\
\hline & Sub-total & 2.45 & & 0.5 & \\
\hline Vitis labruscana & Table & $4.20 \mathrm{a}$ & 0.034 & & 0.025 \\
\hline & Dual-purpose & $5.41 \mathrm{a}$ & 0.021 & & 0.030 \\
\hline & Sub-total & 4.59 & & 0.7 & \\
\hline & & & Correlation & n between & $\mathrm{P}$ and $\mathrm{MF}$ \\
\hline Vitis vinifera & Table & & & $0.32^{\mathrm{NS}}$ & \\
\hline & Wine & & & $-0.06^{\mathrm{NS}}$ & \\
\hline & Dual-purpose & & & $-0.10^{\mathrm{NS}}$ & \\
\hline Vitis labruscana & Table & & & $0.65^{* *}$ & \\
\hline & Dual-purpose & & & $0.48^{\mathrm{NS}}$ & \\
\hline
\end{tabular}

${ }^{2}$ The environmental variance of the value of DFP and MF after log-transformation in each cultivar was commonly estimated at 0.005 and 0.010 , respectively, according to Sato et al. (2000). The standard error $(\mathrm{SE})$ of the values after log-transformation is obtained as the square root of the environmental variance.

${ }^{\mathrm{y}}$ Mean $(\mathrm{n}=10)$.

${ }^{\mathrm{x}}$ Mean separation within columns by least significant difference, $P \leq 0.05$, using log-transformed value

wHeterogeneity within columns was not significant by Bartlett's test , $P \leq 0.05$, using log-transformed value.

Ns, ${ }^{* *}$ Nonsignificant or significant at $P \leq 0.01$, respectively. in the cultivar group having a large mean value for DFP than in the one having a small mean value, however, the variation was similar in every group after log-transformation.

Vinifera cultivars showed a smaller MF $(0.57 \mathrm{~N})$ than labruscana cultivars- $(0.76$ $\mathrm{N})$. The difference of the variances of MF after log-transformation was nonsignificant among the groups, similar to DFP. The large mean values for both the DFP and MF of labruscana cultivars probably come from the labrusca grape, which is the ancestor of the labruscana cultivars. Among the vinifera cultivars, table-use cultivars had a small DFP $(2.06 \mathrm{~mm})$, which was significantly smaller than that of the other vinifera groups $(2.77$ $\mathrm{mm}$ for wine-use cultivars and $2.68 \mathrm{~mm}$ for the dual-purpose cultivars). For the MF, the table-use cultivars had the highest mean value $(0.82 \mathrm{~N})$ among the vinifera group, indicating this group had firm flesh, whereas the wineuse cultivars $(0.35 \mathrm{~N})$ and the dual-purpose cultivars $(0.42 \mathrm{~N})$ had soft flesh. There was no labruscana cultivar with texture exceeding a critical value for crispness shown later. Among labruscana cultivars, the difference in mean MF was nonsignificant between table- and dual-purpose cultivars.

"Crispness" is the most desirable texture for table-use, and cultivars with the crisp flesh texture are important genetic materials for table-grape breeding. The crispness has been previously shown to be a combination of a large MF and a small DFP by puncture tests (Sato et al., 1997). Here, a crisp texture can be identified with $\leq 2.5 \mathrm{~mm}$ for DFP and $\geq 0.9 \mathrm{~N}$ for MF. Among the vinifera table-use cultivars, 'Baladi', 'Cardinal', 'Exotic', 'Flame Seedless', 'Katta Kurgan', 'Malaga', 'Muscat of Alexandria', 'Nimrang', 'Niunai', 'Perlette', and 'Rizamat' had low DFP $(\leq 2.5 \mathrm{~mm})$ and high $\mathrm{MF}(\geq 0.9 \mathrm{~N})$ values, and made up $41 \%$ of 27 vinifera table-use cultivars. In contrast, no wine-use cultivars and only one dual-purpose cultivar ('Terbash') had the flesh exceeding the critical values for crispness. These results indicate that the cultivars with a crisp texture were restricted to a small source within vinifera cultivars.

According to Kozma (1970), the vinifera grape can be classified into three major groups based on use, morphological characteristics, and geographical distribution: 1) orientalis: large oval-berried cultivars with high-temperature requirements for maturity, mainly used for table grapes, distributed in central Asia, Afghanistan, Armenia, and Azerbaidzhan; 2) occidentalis: a small berry wine grape with acid and juicy flesh distributed in France, Germany, Spain, and Portugal;, and 3) pontica: the oldest cultivars originated from the center of viticulture in Transcaucasia; small round berries with juicy and acid flesh distributed in Gulzia, Asia Minor, Greece, and the vicinity of the Black Sea (Kozma, 1970; Mullins et al., 1992). Most of the vinifera table-use cultivars of in this study were from the orientalis group or had orientalis origin. 'Nimrang', 'Niunai', 'Rish Baba', 'Pizzutello Bianco', and 'Muscat of Alexandria' were clearly classified as orientalis by Kozma (1970). Based on their origin, 
'Rosaki' and 'Emperor' can also be classified in the orientalis group (Galet, 1979). Moreover, 11 other cultivars ('Cardinal', 'Exotic', 'Flame Seedless', 'Guzal Kara', 'Hiro Hamburg', 'Italia', 'July Muscat', 'Neo Muscat', 'Perlette', 'Rizamat', and 'Sekirei') were produced by crossbreeding with orientalis type, including 'Thompson Seedless', 'Muscat of Alexandria', and 'Katta Kurgan'. This suggests that the orientalis origin may have been the source of the low DFP and high MF found in table-grape cultivars. Most of wine-use and dual-purpose cultivars have different origin than orientalis. Among the wine-use cultivars, 12 were in the occidentalis group or had occidentalis parentage based on their origin, and two, 'Plavaj' and 'Rkatsiteli' were in the pontica group (Kozma, 1970). Among the dual-purpose cultivars, 'Terbash', 'Tavkveri', and 'Chasselas Dore' were orientalis, but 'Pukhyakovskij', 'Saperavi', and 'Kosarotovskij' ('Pukhyakovskij' o.p.) were pontica (Kozma, 1970). In wine-use cultivars, sugar, acid content, and flavor are the most important factors controlling the wine quality (Reisch and Pratt, 1996). Textural properties, however, are less important qualities for wine making.

Apositive correlation between the DFP and MF afterlog-transformation was obtained in the lubruscana table-use cultivars $\left(r=0.65^{* *}, \mathrm{n}=\right.$ 17). This positive correlation may be one reason that no cultivar had a crisp texture despite a wide variation in DFP and a high mean value in MF, compared to the vinifera cultivars. This linkage suggests that the probability of obtaining offspring with a crisp texture in labruscana breeding is low.

In spite of the fact that some wine-use and dual-purpose vinifera cultivars had higher DFP (e.g., $4.82 \mathrm{~mm}$ for 'Chardonnay', $5.04 \mathrm{~mm}$ for 'Kelner', $4.31 \mathrm{~mm}$ for 'Matrasa', $4.04 \mathrm{~mm}$ for 'Plavaj', $4.39 \mathrm{~mm}$ for 'Koshu', and $4.26 \mathrm{~mm}$ for 'Saperavi'), the correlation between the DFP and MF was insignificant for the vinifera cultivars $\left(r=0.32^{\mathrm{Ns}} \mathrm{n}=27\right.$ for table- use cultivars, $r=-0.06^{\mathrm{Ns}} \mathrm{n}=23$ for wine-use cultivars, and $r=-0.10^{\mathrm{Ns}} \mathrm{n}=12$ for dual-purpose cultivars). There are no cultivars with a tough texture (high values for both DFPand $\mathrm{MF}$ ) among the vinifera cultivars. A possible explanation of the linkage between the DFP and the MF in the labruscana cultivars may be due to the cell wall composition specific to labruscana cultivars, which was afforded by its labrusca parentage. Future studies should closely examine the associations among textural properties and cell wall compositions in order to determine the qualitative differences in texture among labruscana and vinifera cultivars.

In conclusion, puncture tests confirmed that the texture of wine-use and dual-purpose vinifera cultivars was softer than vinifera tableuse cultivars. Cultivars with a desirable crisp texture for table-use were restricted to a narrow germplasm within only the vinifera types.

\section{Literature Cited}

Abbott, J.A., A.E. Watada, and D.R. Massie. 1984 Sensory and instrument measurement of apple texture. J. Amer. Soc. Hort. Sci. 109:221-228.

Alleweldt, G., and J.V. Possingham. 1988. Progress in grapevine breeding. Theor. Appl. Genet. 75: 669-673.

Alleweldt, G.,P. Spiegel-Roy, and B.I. Reisch. 1990. Grapes (Vitis), p. 291-337. In: J.N. Moore and J.R. Ballington, Jr. (eds.). Genetic resources of temperate fruit and nut crops. Acta Hort. 290.

Bailey, L.H and E.Z. Bailey. 1930. Hortus. Macmillan, New York.

Bourne, M.C. 1966. A classification of objective methods for measuring texture and consistency of foods. J. Food Sci. 31:1011-1015.

Bourne, M.C. 1968. Texture profile of ripening pears. J. Food Sci. 33:223-226.

Bourne, M.C. 1979. Texture of temperate fruits. J Texture Std. 10:25-44.

Bourne, M.C. and N. Mondy. 1967. Measurement of whole potato firmness with a Universal Testing Machine. Food Technol. 21:1387-1406.
Brown, S.K. 1988. Assessment of fruit firmness in selected sour cherry genotypes. HortScience 23:882-884.

Cahoon, C.A. 1986. The concord grapes. Fruit. Var. J. 40:106-107.

Einset, J., and C. Pratt. 1975. Grapes, p. 130-153. In: J. Janick and J.N. Moore (eds.). Advances in fruit breeding. Purdue Univ. Press, West Lafayette, Ind.

Friedman, H.H., J.E. Whitney, and A.S. Szczesniak. 1963. The Texturometer-A new instrument for objective texture measurement. J. Food Sci. 28 : 39-396.

Galet, P. 1979. A practical ampelography. Cornell Univ. Press, Ithaca and London.

Hedrick, U.P. 1925. Systematic pomology. Macmillan, New York.

Kozma, P. 1970. Budou saibai no kiso riron (in Japanese). Senbundo Sinkosha, Tokyo.

Lee, C.Y., and M.C. Bourne. 1980. Changes in grape firmness during maturation. J. Texture Std. 11:163-171.

Mullins, M.G., A. Bouquet, and L.E. Williams. 1992. Biology of the grapevine. Cambridge Univ. Press, New York.

Reisch, B.I., and C. Pratt. 1996. Grapes. p. 297-369. In: J. Janick and J.N. Moore (eds.). Fruit breeding. Wiley, New York.

Sato, A., H. Yamane, N. Hirakawa, K. Otobe, and M Yamada. 1997. Varietal differences in the berry texture of grape berries measured by penetration tests, Vitis 36:7-10.

Sato, A., M. Yamada, H. Iwanami, and N. Hirakawa. 2000. Optimal spatial and temporal measurement repetition for reducing environmental variation for berry traits in grape breeding. Sci. Hort. 85:75-83.

Slate, G.S., J. Watson, and A.J. Einset. 1962. Grape varieties. Introduced by the New York State Agr Expt. Sta. 1928-1961. New York Agr. Expt. Sta. Bul. 794:35-47.

Wienberger, J.H. and F.N. Harmon. 1974. Flame Seedless. HortScience 9:602.

Winkler, A.J. 1962. General viticulture. Univ. California Press, Berkeley and Los Angeles.

Yamada, M.H. Yamane, K. Yoshinaga, and Y. Ukai 1993. Optimal spatial and temporal measurement repetition for selection in Japanese persimmon breeding. HortScience 28:838-841. 